\title{
BMJ Open Retrospective analysis of age-adjusted body mass index among pre-pregnant women in the Lithuanian urban area during three decades
}

\author{
Migle Francaite-Daugeliene, ${ }^{1}$ Vladimiras Petrenko, ${ }^{2}$ Dalia Baliutaviciene, ${ }^{3}$ \\ Dzilda Velickiene ${ }^{1}$
}

To cite: FrancaiteDaugeliene M, Petrenko V, Baliutaviciene $\mathrm{D}$, et al. Retrospective analysis of ageadjusted body mass index among pre-pregnant women in the Lithuanian urban area during three decades. BMJ Open 2016;6:e010927. doi:10.1136/bmjopen-2015010927

- Prepublication history for this paper is available online. To view these files please visit the journal online (http://dx.doi.org/10.1136/ bmjopen-2015-010927).

MF-D and DV contributed equally.

Received 13 January 2016 Revised 1 September 2016 Accepted 8 September 2016

CrossMark

For numbered affiliations see end of article.

\section{Correspondence to} Dr Migle FrancaiteDaugeliene; francaite@yahoo. com

\section{ABSTRACT}

Background: The prevalence of maternal obesity at the beginning of pregnancy is increasing. However, there are some studies reporting the stabilisation of obesity epidemic or even the downward trend in the general population.

Objective: To determine the prevalence of overweight and obesity in Lithuanian pre-pregnant women during 3 decades.

Methods: This observational retrospective study included a sample of 2827, women aged 18-44 years who gave birth in 1987-1989, 1996-1997 and 20072010: $861(30.5 \%), 995$ (35.2\%) and 971 (34.3\%), respectively. All women were divided into groups by body mass index (BMI) calculated from self-reported weight and height, and age reported during the first antenatal visit. Quantitative parametric variables were expressed as mean and SD; qualitative variables, as absolute numbers $(n)$ and percentage $(\%)$. For parametric data, analysis of variance (ANOVA) was used. Differences were considered statistically significant at $p<0.05$.

Results: The prevalence of overweight and obesity among women aged 18-24 years decreased from $20.9 \%$ in $1987-1989$ to $9.5 \%$ in $1996-1997$ but increased to $15.7 \%$ in 2007-2010; among women aged $25-34$ years, decreased from $35.5 \%$ in $1987-$ 1989 to $23 \%$ in $1996-1997$ and to $22.4 \%$ in $2007-$ 2010; and among women aged 35-44 years decreased from $64.9 \%$ in $1987-1989$ to $34 \%$ in $1996-1997$ but increased to $45.3 \%$ in 2007-2010. BMI increased with an increasing age $(r=0.254, p<0.05)$. Analysis by separate periods (1987-1989, 1996-1997 and 20072010) revealed a positive correlation between BMI and age at the first antenatal visit in all periods $(r=0.325$, $p<0.01 ; r=0.266, p<0.01 ;$ and $r=0.210, p<0.01$, respectively).

Conclusions: The prevalence of overweight and obesity among pre-pregnant women tended to decrease in the Lithuanian urban area during 3 decades. A slight increase in overweight and obesity documented in 2007-2010 compared with 1996-1997 most likely was caused by older maternal age.

\section{Strengths and limitations of this study}

- The evaluation of body mass index (BMI) among pre-pregnant women during three decades is a long enough period to identify the changes and draw conclusions about trends.

- The size of groups in our study across different decades was greatly similar, and this allowed intercomparison of groups.

- To the best of our knowledge, this is the first publication that presents the downward and stabilising trend in pre-pregnancy BMI.

- The interpretation of data is limited as prepregnancy BMI was calculated from self-reported weight and height, and no detailed measurements of pre-pregnancy weight and height were taken. It is practically impossible to measure prepregnancy weight and height among young healthy women as they rarely visit a clinic, and this leaves the only option to evaluate prepregnancy BMI from self-reported data.

- The diverse distribution of our study participants by age across different periods limited the opportunities for more accurate assessment of obesity prevalence, because older women have been shown to have a higher BMI; however, we could not influence the data as our study was not a randomised study, but a retrospective study of antenatal data of all pregnant women who were observed in the largest outpatient clinics in Kaunas, a Lithuanian urban area.

\section{INTRODUCTION}

The incidence of overweight and obesity increased worldwide progressively over the past five decades, suggesting that a rising trend in prevalence is not a recent phenomenon. ${ }^{12}$ The prevalence of obesity among women of reproductive age has doubled since 1979. ${ }^{3}$ Overweight and obesity are increasing both in high-income, and also in low-income countries. ${ }^{4}$ Recently, there is a 
growing body of evidence about the stabilisation of obesity epidemic or slowing down of body mass index (BMI) trend increases; however, in any case, the prevalence of obesity remains high. ${ }^{5}-{ }^{8} \mathrm{~A}$ declining trend in obesity prevalence is documented more commonly among children, ${ }^{7-10}$ but stabilisation in the prevalence of excess weight is predicted in adults as well. ${ }^{6}{ }^{11}$ Unfortunately, evidence shows that the prevalence of prepregnancy obesity continues to increase and varies by race-ethnicity and maternal age. ${ }^{12} 13$ There are studies reporting that the incidence of maternal obesity at the beginning of pregnancy is also increasing and accelerating and that obesity among pregnant women is becoming one of the most important women's health issues for this decade. ${ }^{14}$ Worldwide data show that the prevalence of maternal obesity (BMI of at least $30 \mathrm{~kg} / \mathrm{m}^{2}$ ) varies from $1.8 \%$ to $25.3 \%$ across the countries. ${ }^{15}$

Maternal obesity can lead to various negative outcomes for both mothers and their offspring. It has been reported to be associated with an increased risk of gestational diabetes, hypertension, pre-eclampsia, stillbirth, fetal macrosomia and caesarean section. ${ }^{16}{ }^{2}{ }^{20}$

Since 1994, several health behaviour surveys have been carried out every 2-4 years during the period of 19942012 within the framework of Finbalt Health Monitor, a collaborative system for monitoring health behaviour in Estonia, Finland, Latvia and Lithuania. The results of this project showed that the prevalence of overweight (BMI $25-29.9 \mathrm{~kg} / \mathrm{m}^{2}$ ) and obesity $\left(\mathrm{BMI}>30 \mathrm{~kg} / \mathrm{m}^{2}\right)$ in the adult female population aged 20-64 years ranged from $44 \%$ to $50 \%$ and from $16 \%$ to $20 \%$, respectively. However, no changes were observed in the prevalence of overweight and obesity among the women aged 20-64 years during the period of 1994-2012. ${ }^{21-23}$ The analysis of epidemiological data gathered during this project from 1994 to 2012 revealed a varying prevalence of overweight and obesity among women of reproductive age, but during final years of the project (2010-2012), a declining trend was observed. These data of the Lithuanian women contradict various literature data reporting an increasing prevalence of overweight and obesity during pre-pregnancy and, therefore, are promising. We aimed at conducting a study to further analyse changes in BMI among women of reproductive age and possible trends of BMI during pre-pregnancy in the Lithuanian urban area.

\section{OBJECTIVE}

To determine the prevalence of overweight and obesity in the Lithuanian pre-pregnant women in the urban area during three decades.

\section{MATERIALS AND METHODS}

This study was part of the GESTAtional Diabetes long term consequences (GESTAD) study, which surveys the influence of gestational diabetes and obesity during pregnancy on the health of women and their offspring. We reviewed antenatal records of 2896 pregnant women who gave birth in 1987-1989, 1996-1997 and 2007-2010, and received maternity care services in two outpatient departments of Kaunas city (Lithuania) with a population of 348000 . Records of women who were younger than 18 years or older than 44 years and those with missing or biologically implausible height and weight were excluded from the analysis. The final study population comprised 2827 women: $861(30.5 \%)$ in $1987-1989,995(35.2 \%)$ 1996-1997 and 971 (34.3\%) in 2007-2010.

Information on age recorded at the first antenatal visit and pre-pregnancy self-reported weight and height was gathered from antenatal records. BMI was calculated from self-reported pre-pregnancy weight and height as the weight in kilograms divided by the square of the height in metres $\left(\mathrm{kg} / \mathrm{m}^{2}\right)$. All the women were divided based on their BMI into the following groups according the WHO classification: underweight women $\left(\mathrm{BMI}<18.5 \mathrm{~kg} / \mathrm{m}^{2}\right)$, women with normal weight (BMI $18.5-24.9 \mathrm{~kg} / \mathrm{m}^{2}$ ), overweight (BMI $25-29.9 \mathrm{~kg} / \mathrm{m}^{2}$ ) and obese women $\left(\mathrm{BMI} \geq 30 \mathrm{~kg} / \mathrm{m}^{2}\right)$. Obesity was categorised as class 1 obesity (BMI $30.0-34.9 \mathrm{~kg} / \mathrm{m}^{2}$ ), class 2 obesity (BMI 35.0 $39.9 \mathrm{~kg} / \mathrm{m}^{2}$ ) and class 3 or morbid obesity (BMI $40 \mathrm{~kg} / \mathrm{m}^{2}$ and more). According to the age, women were divided into the following groups: age from 18 to 24 years, age from 25 to 34 years and age from 35 to 44 years.

A database was created using Microsoft Office Excel. For statistical analysis, data were exported to the statistical package IBM SPSS Statistics, V.21. Quantitative parametric variables are presented as a mean and SD; qualitative variables, as absolute numbers $(n)$ and percentage (\%). Analysis of variance (ANOVA) was employed to compare three or more groups of parametric data. For comparison of two groups, the $\chi^{2}$ test was used. Correlation analysis of parametrical data was performed by Pearson's correlation. To assess the potential effect of age on BMI, ORs were calculated. Differences were considered statistically significant at $\mathrm{p}<0.05$.

\section{RESULTS}

A total of 2827 pregnant women were included in the study population. The final sample size in the analyses included 861 for group 1987-1989 (30.5\%), 995 for group 1996-1997 (35.2\%) and 971 for group 2007-2010 $(34.3 \%)$. The characteristics of women of reproductive age by different periods are shown in table 1 .

Overall, the BMI increased with increasing age of women $(\mathrm{r}=0.254, \mathrm{p}<0.05)$ (figure $1 \mathrm{~A})$. There was a significant positive correlation between BMI and age at the first antenatal visit during all study periods investigated: $\mathrm{r}=0.325 \quad(\mathrm{p}<0.001)$ in 1987-1989 (figure 1B), $\mathrm{r}=0.266$ $(\mathrm{p}<0.001)$ in 1996-1997 (figure 1C) and $\mathrm{r}=0.210$ $(\mathrm{p}<0.001)$ in 2007-2010 (figure 1D).

The women aged 25-34 years and 35-44 years were 2.34 (95\% CI 1.93 to 2.83 ) and 3.39 (95\% CI 2.59 to 4.42) times, respectively, likely to be overweight than their youngest counterparts. 
Table 1 The characteristics of women's age at the first antenatal visit and body mass index (BMI) data in pre-pregnancy by different periods (1987-1989, 1996-1997, 2007-2010) in the Lithuanian urban area

\begin{tabular}{|c|c|c|c|c|}
\hline Characteristic & $\begin{array}{l}1987-1989 \\
(N=861,30.5 \%)\end{array}$ & $\begin{array}{l}1996-1997 \\
(\mathrm{~N}=995,35.2 \%)\end{array}$ & $\begin{array}{l}2007-2010 \\
(\mathrm{~N}=971,34.3 \%)\end{array}$ & p Value \\
\hline Age at the first antenatal visit, mean $\pm S D$, years & $25.6 \pm 5.16$ & $25.26 \pm 4.88$ & $28.37 \pm 5.51$ & $<0.001$ \\
\hline \multicolumn{5}{|c|}{ Age at the first antenatal visit, $n(\%)$} \\
\hline $18-24$ years & $429(49.8)$ & $504(50.7)$ & $255(26.3)$ & $<0.05$ \\
\hline 25-34 years & $375(43.6)$ & $435(43.7)$ & $580(59.7)$ & $<0.05$ \\
\hline $35-44$ years & $57(6.6)$ & $56(5.6)$ & $136(14.0)$ & $<0.05$ \\
\hline Height, mean $\pm S D, c m$ & $1.65 \pm 0.05$ & $1.66 \pm 0.05$ & $1.67 \pm 0.06$ & $<0.001$ \\
\hline Weight, mean \pm SD (range), $\mathrm{kg}$ & $65.28 \pm 10.79(44-123.9)$ & $61.68 \pm 9.88(40-117)$ & $64.87 \pm 12.90(42-127)$ & $<0.001$ \\
\hline $\mathrm{BMI}$, mean $\pm \mathrm{SD}, \mathrm{kg} / \mathrm{m}^{2}$ & $23.9 \pm 3.68$ & $22.14 \pm 3.36$ & $23.05 \pm 4.32$ & $<0.001$ \\
\hline \multicolumn{5}{|l|}{ BMI $\left(\mathrm{kg} / \mathrm{m}^{2}\right), \mathrm{n}(\%)$} \\
\hline$<18.5$ & $21(2.4)$ & $82(8.2)$ & $81(8.3)$ & $<0.05$ \\
\hline $18.5-24.9$ & $580(67.4)$ & $746(75)$ & $659(67.9)$ & $<0.05$ \\
\hline $25-29.9$ & $200(23.2)$ & $136(13.7)$ & $156(16.1)$ & $<0.05$ \\
\hline $30-34.9$ & $52(6.0)$ & $26(2.6)$ & $53(5.5)$ & $<0.05$ \\
\hline $35-39.9$ & $6(0.7)$ & $3(0.3)$ & $19(2.0)$ & $<0.05$ \\
\hline$\geq 40$ & $2(0.2)$ & $2(0.2)$ & $3(0.3)$ & $>0.05$ \\
\hline
\end{tabular}

Table 2 shows the mean BMI of pre-pregnant women by different periods and age groups indicating that the women in the oldest age group (35-44 years) had a significantly higher BMI compared with the younger women $(p<0.001)$. A declining trend in BMI is best seen in the largest age group, which included women aged 25-34 years, where we observed a statistically significant difference comparing 1987-1989 vs 1996-1997 and 1987-1989 vs 2007-2010. However, there was no statistically significant difference in the mean BMI between 1996-1997 and 2007-2010. This indicates a declining and stabilising trend in the prevalence of prepregnancy obesity in the Lithuanian urban area.

Table 3 indicates the distribution of the study participants by different BMI, periods and age groups. In subgroup analyses, the prevalence of overweight and obesity among women aged 18-24 years decreased from $20.9 \%$ in 1987-1989 to $9.5 \%$ in 1996-1997 but increased to $15.7 \%$ in $2007-2010 \quad(p<0.05)$. The proportion of women aged 25-34 years with a BMI of more than $25 \mathrm{~kg} / \mathrm{m}^{2}$ decreased from $35.5 \%$ in $1987-1989$ to $23 \%$ in 1996-1997 $(\mathrm{p}<0.05)$ and to $22.4 \%$ in $2007-2010$ $(\mathrm{p}<0.05)$. Among women aged $35-44$ years, the prevalence of overweight and obesity decreased from $64.9 \%$ in $1987-1989$ to $34 \%$ in $1996-1997 \quad(\mathrm{p}<0.05)$ but increased to $45.3 \%$ in $2007-2010 \quad(p<0.05)$. A slight increase in the prevalence of overweight and obesity seen in 2007-2010 compared with 1996-1997 was not statistically significant and most likely occurred due to older maternal age.

Overall, the prevalence of overweight and obesity across to the periods decreased from 30.1\% in 19871989 to $16.8 \%$ in $1996-1997$ and $23.8 \%$ in $2007-2010$.

\section{DISCUSSION}

The rapid growth in obesity represents a major public concern. A significant increase in obesity during the past 40 years has been documented in developed and developing countries. ${ }^{24}$ The prevalence of overweight and obesity is increasing among women of reproductive age as well. ${ }^{24}$ Data from some countries have shown a decline or stabilisation in obesity levels, especially among children. ${ }^{7}$ Recently, a declining trend in the prevalence of obesity has been reported in some populations of youth in Europe and the USA, and the rate of increase in adult BMI has slowed down in England. ${ }^{6}$ Unfortunately, the prevalence of pre-pregnancy obesity continues to increase and varies by race-ethnicity and maternal age. ${ }^{12} 13$

In our study, we chose to analyse the BMI of reproductive-age women as it is very important both for their own health, and also for their offspring-the future generation. The mechanisms that link maternal obesity to obesity in offspring are not completely elucidated yet, but gestational programming could play an important role. ${ }^{25}{ }^{27}$ Among women of childbearing age, it is of paramount importance due to its association with multiple adverse health outcomes for the mother and the fetus once a woman becomes pregnant. ${ }^{16}$

Obesity is an issue of particular concern in the Baltic countries, where data from multinational surveys have shown that the rates of obesity are among the highest in the world. Data from the WHO Multinational MONItoring of trends and determinants in CArdiovascular disease (MONICA) project, collected between 1983 and 1988, placed five centres in the former Soviet Union among the top six positions of 48 centres worldwide in terms of obesity among women, with Kaunas in Lithuania occupying the highest position. ${ }^{28}$ A study by Pomerleau et al, which was conducted in Lithuania, Latvia and Estonia in 1997, identified obesity to be a major health problem in the Baltic countries, particularly among Lithuanian and Latvian women. More than half $(51 \%)$ of female respondents from Lithuania had excess weight, that is, were 

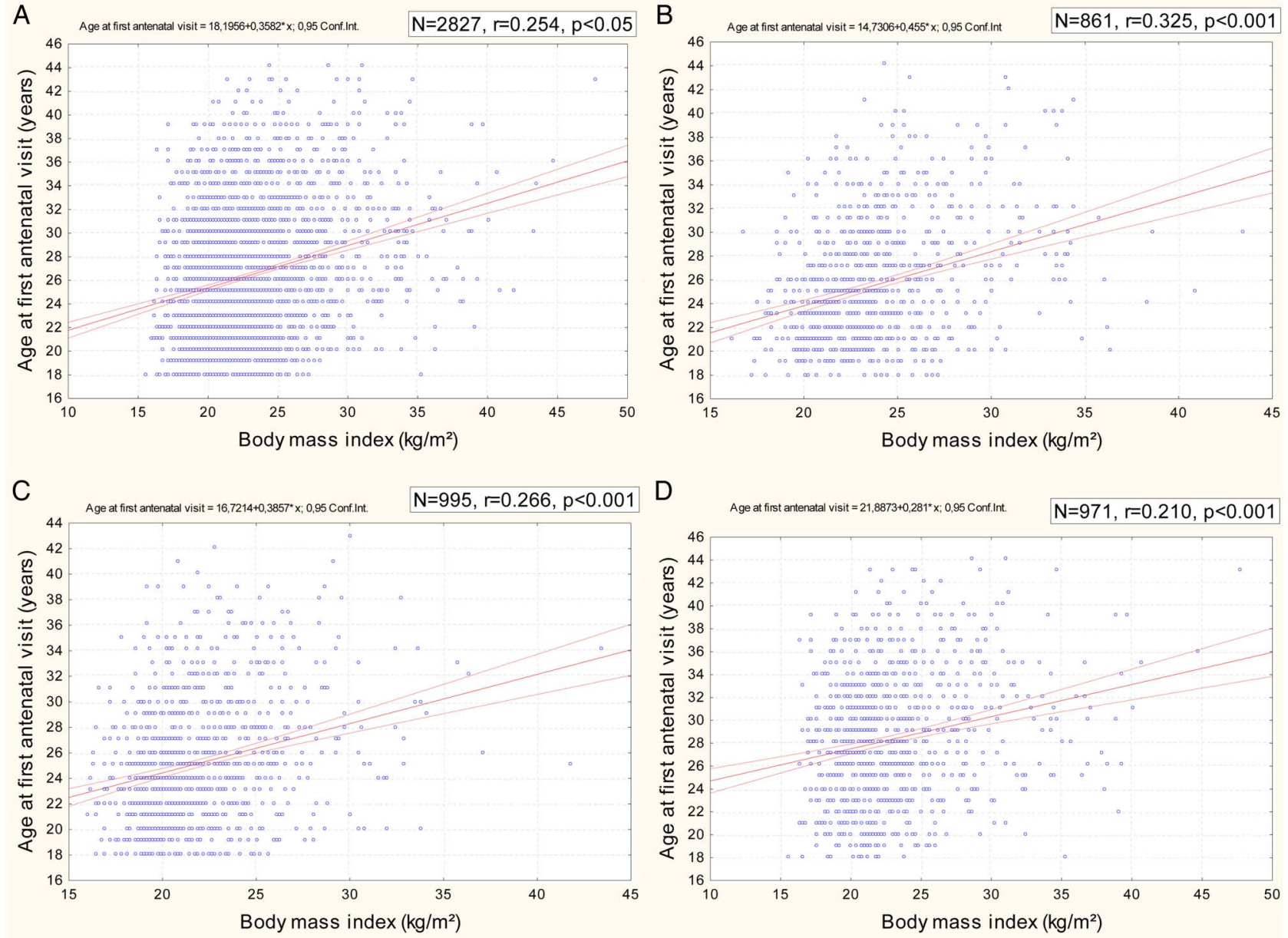

Figure 1 Correlation between body mass index and age at the first antenatal visit during all three periods (A), 1987-1989 (B), 1996-1997 (C) and 2007-2010 (D).

Table 2 Body mass index of pre-pregnant women by different periods (1987-1989, 1996-1997, 2007-2010) and age groups in the Lithuanian urban area

\begin{tabular}{|c|c|c|c|c|}
\hline \multirow[b]{2}{*}{ Age groups (years) } & \multicolumn{3}{|l|}{ Period } & \multirow[b]{2}{*}{ p Value } \\
\hline & 1987-1989 & 1996-1997 & $2007-2010$ & \\
\hline $18-24$ & $\begin{array}{l}22.89 \pm 3.084 \\
(22.60 \text { to } 23.19)\end{array}$ & $\begin{array}{l}21.34 \pm 2.78 \\
\text { (21.10 to } 21.59)\end{array}$ & $\begin{array}{l}22.03 \pm 3.65 \\
\text { (21.57 to } 22.48)\end{array}$ & $\begin{array}{r}<0.001,1987-1989 \text { vs } 1996-1997 \\
<0.001,1987-1989 \text { vs } 2007-2010 \\
0.004,1996-1997 \text { vs } 2007-2010\end{array}$ \\
\hline $25-34$ & $\begin{array}{l}24.63 \pm 3.91 \\
(24.23 \text { to } 25.03)\end{array}$ & $\begin{array}{l}22.83 \pm 3.75 \\
\text { (22.48 to } 23.19)\end{array}$ & $\begin{array}{l}23.02 \pm 4.26 \\
\text { (22.67 to } 23.37)\end{array}$ & $\begin{array}{r}<0.001,1987-1989 \text { vs } 1996-1997 \\
<0.001,1987-1989 \text { vs } 2007-2010 \\
0.450,1996-1997 \text { vs } 2007-2010\end{array}$ \\
\hline $35-44$ & $\begin{array}{l}26.60 \pm 3.83 \\
\text { (25.59 to } 27.62)\end{array}$ & $\begin{array}{l}23.86 \pm 3.24 \\
(22.99 \text { to } 24.73)\end{array}$ & $\begin{array}{l}25.10 \pm 4.97 \\
(24.26 \text { to } 25.95)\end{array}$ & $\begin{array}{l}0.002,1987-1989 \text { vs } 1996-1997 \\
0.068,1987-1989 \text { vs } 2007-2010 \\
0.055,1996-1997 \text { vs } 2007-2010 \\
\end{array}$ \\
\hline
\end{tabular}

overweight or obese. The proportion of women who were obese in Latvia and Lithuania was approximately three times higher than the proportion of such women in Estonia. The difference was especially considerable among women aged <35 years, with more than four times as many women in Lithuania being obese compared with those in Estonia. ${ }^{29}$ However, it is worth noting that in this survey, the proportion of Lithuanian women who were obese was smaller than in the earlier MONICA study. ${ }^{28} 29$

The study by Pomerleau et al also evaluated BMI by different age groups, and for comparison with our results, only the data on Lithuanian women of reproductive age were extracted. In the study by Pomerleau 


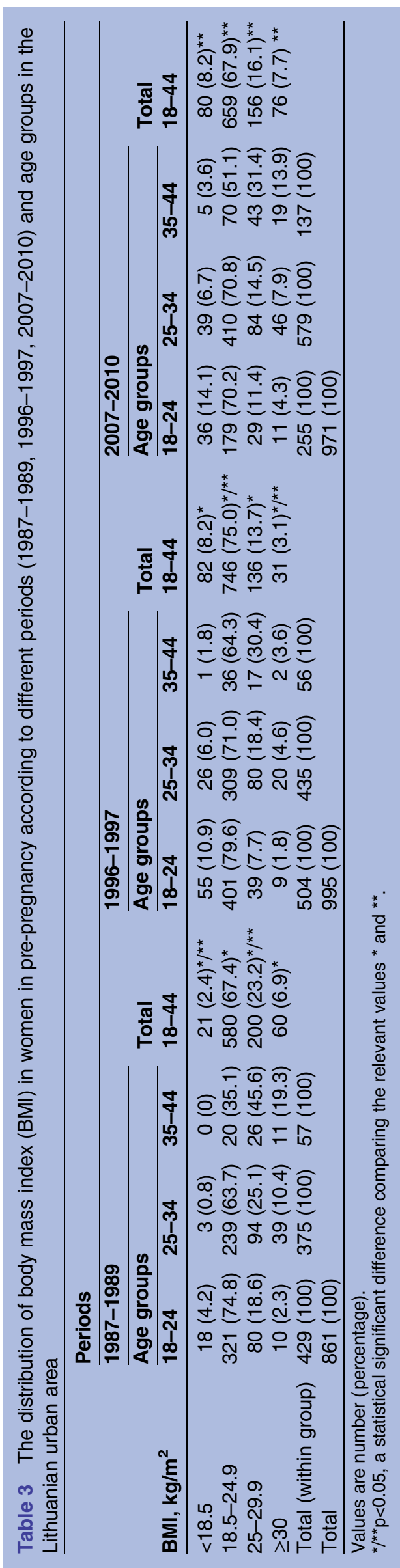

et $a l^{29}$ the BMI of women aged 19-34 years and 3549 years was $23.2 \pm 4.6 \mathrm{~kg} / \mathrm{m}^{2}$ and $25.7 \pm 4.6 \mathrm{~kg} / \mathrm{m}^{2}$, respectively, and $28.1 \%$ and $11.2 \%$ of Lithuanian women aged $19-49$ years $(\mathrm{N}=751)$ were overweight and obese, respectively. The analysis of epidemiological data gathered during the Lithuanian health behaviour monitoring project from 1994 to 2012 revealed a varying prevalence of overweight and obesity among women of reproductive age, but during recent years (2010-2012) a declining trend was observed. ${ }^{21-23}$ Our results showed a decreasing trend in BMI among pre-pregnant women ( $\leq 34$ years and $\geq 35$ years): from $23.76 \pm 3.49$ and 26.60 \pm 3.83 in $1987-1989$ to $22.52 \pm 3.95$ and $25.10 \pm 4.97$ in 2007-2010, respectively. The prevalence of obesity among women aged 18 to 44 years decreased from $6.9 \%$ in $1987-1989$ to $3.1 \%$ in $1996-1997$ and increased to $7.7 \%$ in 2007-2010. Moreover, the merged prevalence of overweight and obesity decreased from $30.1 \%$ in 1987 1989 to $16.8 \%$ in $1996-1997$ but increased to $23.8 \%$ in 2007-2010.

Several limitations should be considered while interpreting the results of our study. First, the interpretation of our data is limited as pre-pregnancy BMI was calculated from self-reported weight and height, and no detailed measurements of pre-pregnancy weight and height were taken. On the other hand, some investigators have observed that self-reported pre-pregnancy weight and weight measured at the first prenatal visit result in identical classification of pre-pregnancy BMI status. ${ }^{30-32}$ It is common to evaluate self-reported pre-pregnancy data in order to avoid possible changes in weight occurring during the first trimester of pregnancy. Most women come for their first antenatal visit early in their pregnancy, that is, before the 12th week. During the normal course of pregnancy, a woman may already gain some weight, but in cases of hyperemesis, the weight can be lower. This means that some women will exceed a BMI of $>30 \mathrm{~kg} / \mathrm{m}^{2}$ due to weight gain of a few kilos, and some other women who lost weight will not be considered as obese. To avoid potential bias, pre-pregnancy BMI calculated from self-reported weight and height was analysed in our study. It is practically impossible to measure prepregnancy weight and height among young healthy women as they rarely visit a clinic, as well as the possible unplanned pregnancies, and this leaves the only option to evaluate pre-pregnancy BMI from self-reported data.

The diverse distribution of our study participants by age across different periods limited the opportunities for more accurate assessment of obesity prevalence, because older women have been shown to have a higher BMI. $^{33}{ }^{34}$ The evaluation of BMI among women older than 35 years is complicated as the number of pregnant women in 1987-1989 and 1996-1997 was two times smaller than that in 2007-2010. A slightly (not significantly) higher pre-pregnancy BMI in 2007-2010 compared with 1996-1997 is likely to be determined by older age associated with decreased physical activity, sedentary lifestyle and changes in hormone levels, but not 
by the particular period. We could not influence the data as our study was not a randomised study, but a retrospective study of antenatal data of all pregnant women who were observed in the largest outpatient clinics in Kaunas, a Lithuanian urban area. Analysis of our data has revealed that recently women are giving birth being rather older than previously. Literature data confirm that during 2001-2010 in Kaunas (Lithuania), the percentage of pregnant women younger than 25 years decreased from $35 \%$ to $16 \%$, while the proportion of pregnant women aged 25-39 years increased from 56\% to $72 \% .{ }^{35}$ To assess the potential modifying effects of age on BMI, women were assigned to various age groups.

Comparison of the results of the study by Pomerleau et $a l$, an epidemiological Lithuanian health behaviour monitoring project and our study revealed a downward trend in the prevalence of overweight and obesity among women of reproductive age. These data contradict various literature sources indicating an increasing prevalence of overweight and obesity during prepregnancy and, therefore, are encouraging. To the best of our knowledge, this is the first publication that presents the downward and stabilising trend in prepregnancy BMI. These promising data could be determined by public health promotion, improvement in social health, organisation of physical activity campaigns, improved access to physical activity and provision of more information about harmful effects of obesity on the body and could mean effective prevention of obesity. However, it also may be only a temporary phenomenon mainly caused by the media that has recently been promoting very lean body. Therefore, the monitoring of future trends in BMI of women is of crucial importance.

In summary, global activity is needed for more effective prevention of obesity. The results of our study are encouraging to further implement preventive strategies, disseminate information about the principles of healthy nutrition and promote physical activity. Talking about future generations, the early-life environment may represent a critical period for which intervention strategies could be developed to enchain a current obesity epidemic; therefore, it is very important for obese women of reproductive age to plan pregnancy. Overweight and obese women should receive assessment and counselling before pregnancy with an attitude towards specific information regarding the maternal and fetal risks of obesity in pregnancy. Moreover, they might benefit from regular visits to a dietician for dietary and physical activity recommendations. Our purpose should be a vicious circle of obesity closing.

\section{CONCLUSION}

The prevalence of overweight and obesity among prepregnant women tended to decrease in the Lithuanian urban area during three decades. A slight increase in overweight and obesity documented in 2007-2010 compared with 1996-1997 most likely was caused by older maternal age.

Author affiliations

${ }^{1}$ Institute of Endocrinology, Lithuanian University of Health Sciences, Kaunas, Lithuania

${ }^{2}$ Department of Endocrinology, Lithuanian University of Health Sciences Kaunas Clinics, Kaunas, Lithuania

${ }^{3}$ Department of Obstetrics and Gynaecology, Lithuanian University of Health Sciences Kaunas Clinics, Kaunas, Lithuania

Contributors MF-D acquired, analysed and interpreted data as well as drafted the manuscript. VP and DB acquired, analysed and interpreted data as well as contributed to the discussion. DV designed the study, contributed to the discussion and made a critical revision of the manuscript.

Funding The article would be financially supported by the Research Council of Lithuania, National Research Program of Scientists Projects Group (contract number MIP-14192).

Competing interests None declared.

Ethics approval Kaunas Regional Bioethics Committee, Lithuania (number BE-2-49).

Provenance and peer review Not commissioned; externally peer reviewed.

Data sharing statement No additional data are available.

Open Access This is an Open Access article distributed in accordance with the Creative Commons Attribution Non Commercial (CC BY-NC 4.0) license, which permits others to distribute, remix, adapt, build upon this work noncommercially, and license their derivative works on different terms, provided the original work is properly cited and the use is non-commercial. See: http:// creativecommons.org/licenses/by-nc/4.0/

\section{REFERENCES}

1. Parikh NI, Pencina MJ, Wang TJ, et al. Increasing trends in incidence of overweight and obesity over 5 decades. Am J Med 2007;120:242-50.

2. Obesity: preventing and managing the global epidemic. Report of a WHO consultation. World Health Organ Tech Rep Ser 2000;894: i-xii, 1-253.

3. WHO: World Health Organization. Global database on body mass index. 2009.

4. $\mathrm{Ng} \mathrm{M}$, Fleming $\mathrm{T}$, Robinson $\mathrm{M}$, et al. Global, regional, and national prevalence of overweight and obesity in children and adults during 1980-2013: a systematic analysis for the Global Burden of Disease Study 2013. Lancet 2014;384:766-81.

5. Ogden CL, Carroll MD, Kit BK, et al. Prevalence of childhood and adult obesity in the United States, 2011-2012. JAMA 2014;311:806-14

6. Sperrin M, Marshall AD, Higgins V, et al. Slowing down of adult body mass index trend increases in England: a latent class analysis of cross-sectional surveys (1992-2010). Int J Obes (Lond) 2014;38:818-24.

7. Olds T, Maher C, Zumin S, et al. Evidence that the prevalence of childhood overweight is plateauing: data from nine countries. Int J Pediatr Obes 2011;6:342-60.

8. Aeberli I, Henschen I, Molinari L, et al. Stabilization of the prevalence of childhood obesity in Switzerland. Swiss Med Wkly 2010;140:w13046.

9. Sedej K, Kotnik P, Avbelj Stefanija M, et al. Decreased prevalence of hypercholesterolaemia and stabilisation of obesity trends in 5-year-old children: possible effects of changed public health policies. Eur J Endocrinol 2014:170:293-300.

10. Rolland-Cachera MF, Peneau S. Stabilization in the prevalence of childhood obesity: a role for early nutrition? Int J Obes (Lond) 2010;34:1524-5.

11. Schneider H, Dietrich ES, Venetz WP. Trends and stabilization up to 2022 in overweight and obesity in Switzerland, comparison to France, UK, US and Australia. Int J Environ Res Public Health 2010;7:460-72.

12. England PH: 2013. http://www.noo.org.uk/NOO_about obesity/ maternal_obesity_2015/prevalence 
13. Fisher SC, Kim SY, Sharma AJ, et al. Is obesity still increasing among pregnant women? Prepregnancy obesity trends in 20 states, 2003-2009. Prev Med 2013;56:372-8.

14. Heslehurst $\mathrm{N}$, Ells LJ, Simpson $\mathrm{H}$, et al. Trends in maternal obesity incidence rates, demographic predictors, and health inequalities in 36,821 women over a 15-year period. BJOG 2007;114:187-94.

15. Guelinckx I, Devlieger R, Beckers K, et al. Maternal obesity: pregnancy complications, gestational weight gain and nutrition. Obes Rev 2008;9:140-50.

16. Siega-Riz AM, King JC. Position of the American Dietetic Association and American Society for Nutrition: obesity, reproduction, and pregnancy outcomes. J Am Diet Assoc 2009;109:918-27.

17. Wild SH, Byrne CD. ABC of obesity. Risk factors for diabetes and coronary heart disease. BMJ 2006;333:1009-11.

18. Leddy MA, Power ML, Schulkin J. The impact of maternal obesity on maternal and fetal health. Rev Obstet Gynecol 2008;1:170-8.

19. Marshall NE, Guild C, Cheng YW, et al. The effect of maternal body mass index on perinatal outcomes in women with diabetes. Am $J$ Perinatol 2014;31:249-56.

20. Weiss JL, Malone FD, Emig D, et al. Obesity, obstetric complications and cesarean delivery rate-a population-based screening study. Am J Obstet Gynecol 2004;190:1091-7.

21. Grabauskas V, Klumbiene J, Petkeviciene J, et al. Health behaviour among Lithuanian adult population. 2006.

22. Grabauskas V, Klumbiene J, Petkeviciene J, et al. Health behaviour among Lithuanian adult population. 2010.

23. Grabauskas V. Klumbiene J, Petkeviciene J, et al. Health behaviour among Lithuanian adult population. 2012.

24. Catalano PM. Obesity, insulin resistance, and pregnancy outcome. Reproduction 2010;140:365-71.
25. Li M, Sloboda DM, Vickers MH. Maternal obesity and developmental programming of metabolic disorders in offspring: evidence from animal models. Exp Diabetes Res 2011;2011:592408.

26. Youngson NA, Morris MJ. What obesity research tells us about epigenetic mechanisms. Phil Trans $R$ Soc $B$ 2012;368:20110337.

27. Martin-Gronert MS, Ozanne SE. Early life programming of obesity. Med Wieku Rozwoj 2013;17(1):7-12

28. Geographical variation in the major risk factors of coronary heart disease in men and women aged 35-64 years. The WHO MONICA Project. World Health Stat Q 1988;41:115-40.

29. Pomerleau J, Pudule I, Grinberga D, et al. Patterns of body weight in the Baltic Republics. Public Health Nutr 2000;3:3-10.

30. Hedderson MM, Gunderson EP, Ferrara A. Gestational weight gain and risk of gestational diabetes mellitus. Obstet Gynecol 2010;115:597-604.

31. Harris HE, Ellison GT. Practical approaches for estimating prepregnant body weight. J Nurse Midwifery 1998;43:97-101.

32. Holland E, Moore Simas TA, Doyle Curiale DK, et al. Self-reported pre-pregnancy weight versus weight measured at first prenatal visit: effects on categorization of pre-pregnancy body mass index. Matern Child Health J 2013;17:1872-8.

33. Baum CL II, Ruhm CJ. Age, socioeconomic status and obesity growth. $J$ Health Econ 2009;28:635-48.

34. Gao Y, Ran XW, Xie XH, et al. Prevalence of overweight and obesity among Chinese Yi nationality: a cross-sectional study. BMC Public Health 2011;11:919.

35. Tatariuniene A, MG SJ, Ramanauskas E. Kauno miesto bendrasis planas: esamos būklès analizè. 2011;16:II. 